Corresponding Author: Dr. Bashir Abdrhman Bashir Mohammed;

Associate Professor of Hematology, Chairman of Hematology Department, Faculty Medical Laboratory Sciences, Port Sudan Ahlia College, Port Sudan, Sudan Tel: 00249912358772 Fax: 00249311826537 email:

bashirbashir17@hotmail.com

Received 2 July 2020

Accepted 26 August 2020

Published

30 September 2020

Production and Hosting by Knowledge E

(c) Bashir A. Bashir and Abubaker El-dirdiri. This article is distributed under the terms of the Creative

Commons Attribution

License, which permits

unrestricted use and

redistribution provided that the original author and

source are credited.

Editor-in-Chief:

Prof. Mohammad A. M. Ibnouf

G OPEN ACCESS

\section{Post-Chikungunya Joint Pain Sequelae: A Sudanese Single-Center Study}

\author{
Bashir A. Bashir ${ }^{1}$ and Abubaker El-dirdiri² \\ ${ }^{1}$ Hematology Department, Faculty of Medical Laboratory Sciences, Port Sudan Ahlia College, \\ Port Sudan, Sudan \\ ${ }^{2}$ Orthopaedic department, Port Sudan Teaching Hospital, Port Sudan, Sudan
}

\section{Abstract}

Background: Chikungunya has recently been reported by the WHO to account for many cases in Sudan. The infection is extremely symptomatic, with fever, skin rash, and incapacitating arthralgia, which can promote chronic arthritis and rheumatism in older patients. A few studies on chronic pain owing to the Chikungunya virus (CHIKV) infection have been issued. The aim of this study was to outline the laboratory findings and the physical symptom frequency of joint pain of the current Sudanese CHIKV outbreak, and evaluate its impact on the individual.

Methods: This cross-sectional study included 23 CHIKV-confirmed patients attending a Sudanese single private medical center between March and September 2019. The included patients were checked for rheumatoid factor (RF) value, C-reactive protein (CRP) titer, erythrocyte sedimentation rate (ESR) value, and uric acid (UA) level. Physical scrutiny was conducted and persistent symptoms were registered.

Results: The significant rheumatologic conditions were polyarthralgia $39.1 \%$, polyarthritis $21.7 \%$, arthralgia $17.4 \%$, arthritis $13 \%$, and osteoarthritis $8.8 \%$. Swelling signs were noted in $21.9 \%$ of the patients. Joints implicated were knees $59.4 \%$, wrists $56.3 \%$, fingers $50 \%$, shoulders $37.5 \%$, feet $34.4 \%$, ankles $31.3 \%$, spine $18.8 \%$, and elbow 9.4\%. CRP, RF, and ESR were significantly increased in patients with persistent joints pain versus non-persistent joint pain patients $(P=0.000,0.002,0.008$, respectively). Whereas the UA was insignificant $(P=0.920)$.

Conclusion: Knee joint pain remarks a significant dilemma post-CHIKV. It is noted that these remarks were linked with the risk of subsequently creating chronic sequelae. Polyarthralgia was the dominant inflammatory sequel post-Chikungunya infection.

Keywords: CHIKV, Arthritis, Arthralgia, Polyarthralgia, Polyarthritis, Sudan

\section{Introduction}

Chikungunya virus (CHIKV) infection is a mosquito-borne disease that can cause prompt chronic articulations pain and arthritis [1]. CHIKV is an arbovirus transmitted by the bite of the casualty female of mosquitoes, Aedes aegypti, and Aedes albopictus. Patients with 
severe contagion present with fever, headache, myalgia, rash, and joint pain. Previous outbreaks have been documented in Africa, Asia, Europe, and the Indian and Pacific Ocean islands and even Sudan [2]. CHIKV can cause extreme morbidity and, since 2005, scanty fatal cases were quantified [3]. Sudan is an African nation that fringes the Red Sea and seven nations. The atmosphere in Sudan is hot and dry. In the year 2018, 15 of Sudan's 18 States have been influenced by overwhelming downpours and floods among June and early November [2]. The circumstance made great ground for mosquitoes' reproduction. The distribution of CHIKV in the overall public is obscure in Sudan. Sporadic instances of CHIKV having co-infection with Dengue Fever have been accounted for from Sudan [2]. Nonetheless, high densities of Aedes aegypti have been recognized in all States of Sudan excluding Khartoum and Northern States [3]. CHIKV causes both acute and chronic disabling trouble. Beginning weeklong prostrated fevers are predominantly followed by musculoskeletal and joint pain, frank arthritis, and, more infrequently eye inflammation, vision loss, Guillain-Barre Syndrome, paralysis, vasculitis, encephalitis, hepatitis, and/or myopericarditis [4]. The term "Chikungunya" signifies "that which bends up" about the extreme arthralgia related to the intense period of infection and the subsequent posture of those afflicted. To date, the exact mechanism for CHIKV's incapacitating sequelae stay to be completely obscure. Underlying comorbidities, for example, cardiovascular disease, hypertension, concomitant osteoarthritis, obesity, and diabetes have been distinguished as conceivably expanding the seriousness of CHIKV disease. Likewise, age at the time of extreme infection has been accounted for by many examiners to be predictive of persistent arthralgia or arthritis after CHIKV infection [5]. Research conducted in the American outbreak explored that 30-70\% of CHIKV infected patients experience persistent joint pain months or years after their severe sickness. There have been a few statements of the recurrence of chronic joint pain in American [6]. In this study, we examined the laboratory findings and the physical symptom frequency of joint pain of the current Sudanese CHIKV outbreak and its effect on the individual.

\section{Patients and Methods}

Thirty-two patients with clinically and laboratory-confirmed CHIKV infection were recorded as a portion of a prospective cross-sectional study in the period from March to September 2019. This study was started six months after the end of the current Sudanese outbreak. The diagnosis of CHIKV was immunologically verified by enzymelinked immunosorbent assay (ELISA). A baseline survey was documented to ascertain exposure history, rheumatologic symptoms, duration of symptoms, number of joints 
affected, and comorbidities. Patients defined as suffering from joint pain were taken to complete the arthritis disease activity score questionnaire [7]. Individuals who already have features or confirmed for arthritis, systemic lupus erythematosus (SLE), Sjogren's syndrome, sarcoidosis, chronic infection, and cancer were excluded from this study. All enrolled CHIKV patients were screened for rheumatoid factor (RF) titer, C-reactive protein (CRP) titer, erythrocyte sedimentation rate (ESR), and serum uric acid level.

\subsection{Arthritis Severity Score}

The disease activity sequelae in patients were estimated using the internationally validated disease activity score recommended by the American College of Rheumatology [7].

\subsection{Quality Control}

Standard operational procedures (SOPs) were carefully pursued, and quality control materials were applied for all serological tests. Moreover, the research facility quality was guaranteed by well-prepared experts and supervision during sample processing.

\subsection{Sample Size calculation}

The gauging of sample size was calculated using a cross-sectional statistic formula at $95 \% \mathrm{Cl}, 18 \%$ marginal errors with $50 \%$ of $\mathrm{CHIKV}$ distributed in a similar study [8]. A 10\% unresponsive rate was likewise used to turn away any errors and expand the dependability of the findings. The sample size was adjusted to 32 .

\subsection{Laboratory analysis}

For each patient, $3 \mathrm{ml}$ venous blood samples were gathered under an aseptic condition in sterile plain containers for performing Uric acid level, RF and CRP titers. $2 \mathrm{ml}$ venous blood samples added to 3.2\% Tri-sodium citrate containers in a proportion of 1: 4 forwarded to carried out ESR (Westergren technique). 


\subsection{Data analysis}

Data are summarized as mean \pm standard deviation for continuous variables and as the number (percentage) for categorical variables. The Kolmogorov-Smirnov test was employed to assess the distributions of continuous variables and it exhibited that the variables were normally distributed for each group. Nonparametric tests, Mann-Whitney test and Wilcoxon signed rank test were used to compare CRP, RF, ESR, and UA between patients with persistent joint pain and non-persistent joint pain. The Chi-squared test or Fisher's exact test was conducted for rheumatological symptoms and diagnosis. Linear regression was applied to explore the provoke of CRP and RF with the duration of the disease. The correlation between variables was measured by Spearman's rank-order correlation analysis. $\mathrm{P}<0.05$ was taken statistically significant. Data were analyzed employing statistical package for social science (SPSS 24.0 version, IBN, Chicago, USA).

\section{Results}

A total of 32 participants were enrolled and fulfilled the criteria of the study. Of 32 patients, 16 (50\%) were males and 16 (50\%) were females. The baseline categories of the confirmed cases were highlighted in (Table 1). The most frequent baseline comorbidity was diabetes (13\%). The most commonly influenced joints were knees joint, wrists joint, fingers joint, and shoulders joint (Table 2). The underlying joint pain during the intense infection lasted a median of 3 months, and numerous patients had sporadic and persistent joint pain after the initial infection. At the point when patients were arranged by sex, it was noted that both genders were equally prone to have CHIKV infection symptoms.

During follow-up, the median duration of joint pain was documented as 3 months. 23 out of 32 patients (71.9\%) had persistent joint pain. About $48 \%$ of patients with persistent joint pain were female (Table 1). This study reported up to 6 joint involvements, including the number of joints implicated and the span of joint symptoms. The elementary infection was observed the overwhelmed majority of CHIKV infection among the studied 25 (78.1\%), whereas recurrent infection was seen only in 7 (21.9\%) of the patients. According to the disease activity score, most of the cases in this study are polyarthralgia (39.1\%) followed by polyarthritis (21.7\%), arthralgia (17.4\%), and arthritis (13.0\%) (Table 1).

The difference between the CHIKV infected patients with persistent joint pain and non-persistent joint pain was found to be significant in CRP, RF, and ESR ( $P=0.000$, 0.002 , and 0.008 , respectively). While Uric acid was insignificant between the two 
groups ( $P=0.920$ ) (Table 1). ESR was significantly increased in persistent joint pain (ranged 25 - 50) in 50\% of patients. ESR. CRP and RF titer values were ranging between 3 and 60 (median $14.3 \mathrm{mg} / \mathrm{liter}$ ) and from 4.7 - 24 (median $11.2 \mathrm{IU} / \mathrm{ml}$ ), respectively. $34.4 \%$ of patients with persistent joint pain had a significant increase in RF value which indicates inflammatory arthritis. 59.4\% of persistent joint pain was concerned with high CRP titer levels. 8 (25\%) of patients had high RF and CRP titer values. Moreover, CRP was not affected by the duration of the disease $(P=0.152)$, unlike RF which was statistically increased with the increasing duration of the illness $(P=0.013)$. This was highlighted by regression analysis (Figure 1, 2).

Among the participants in the present report, the most frequent joint pain symptoms recorded were knee joint pain which was experienced by $59.4 \%$ of the patients followed by wrist joint pain $56.3 \%$, fingers joint pain $50 \%$, shoulder joint pain $37.5 \%$, feet joint pain $34.4 \%$, ankle joint pain $31.3 \%$, swelling $21.9 \%$, spine joint pain $18.8 \%$, and elbow joint pain 9.4\%. Interestingly, the knee joint pain symptom represented the signature symptom post-CHIKV infection $(P=0.000)$ as well as wrist joint pain $(P=0.001)$, fingers joint pain $(P=0.002)$ (Table 2). However, it is great to note that these remarks were linked with the risk of subsequently creating chronic sequelae. The statistical elaboration of findings with the rheumatologic conditions is illustrated in Table 3.

In this report, age was found to be significantly correlated with the number of joint affected $(r=0.442 / P<0.011)$, underlying disease $(r=-0.482 / P<0.005)$, and shoulder joint pain ( $r=-0.361 / P=0.042)$, and negatively correlated with RF level, CRP level, and ESR level $(r=0.125 / P<0.494, r=-0.032 / P=0.862, r=0.176 / P=0.336$, respectively). A positive correlation was seen in the number of joint affected by ESR level, shoulder joint pain, and swelling $(r=-0.603 / P<0.000, r=-0.501 / P=0.003, r=-0.471 / P=$ 0.007 , respectively). Furthermore, a significant correlation was also noted in CRP level with the number of joint affected, ESR level, knee joint pain, and shoulder joint pain ( $r$ $=-0.720 / P=0.000, r=0.700 / P=0.000, r=-0.352 / P=0.048, r=0.378 / P=0.033$, respectively), and negatively correlated with the number of joint affected, underlying disease, RF level, and swelling $(r=-0.004 / P=0.985, r=0.129 / P=0.483, r=0.197 / P$ $=0.280, r=0.249 / P=0.115$, respectively). On the other hand, the ESR was positively correlated with CRP $(r=0.545 / P=0.001)$ and negatively correlated with RF ( $r=0.249$ / $P=0.169)$. 
TABLE 1: Baseline characteristics of the patients serologically confirmed CHIKV classified according to joint pain status

\begin{tabular}{|c|c|c|c|c|}
\hline Categories & Subcategory & $\begin{array}{l}\text { Persist Joint } \\
\text { pains } \\
n=23\end{array}$ & $\begin{array}{l}\text { No persist joint } \\
\text { pain } \\
n=9\end{array}$ & $\mathbf{P}$ \\
\hline Age & Mean \pm SD year & $43.56 \pm 16.97$ & $33.22 \pm 9.61$ & 0.097 \\
\hline Sex & $\begin{array}{l}\text { Male } \\
\text { Female }\end{array}$ & $\begin{array}{l}12(52.2 \%) \\
11(47.8 \%)\end{array}$ & $\begin{array}{l}4(44.4 \%) \\
5 \text { (55.6\%) }\end{array}$ & 0.705 \\
\hline \multicolumn{5}{|c|}{ Prior comorbidity } \\
\hline & $\begin{array}{l}\text { Hypertension } \\
\text { (HTN) } \\
\text { Diabetes (DM) } \\
\text { HTN + DM } \\
\text { Gout } \\
\text { None }\end{array}$ & $\begin{array}{l}1(4.35 \%) \\
3(13.04 \%) \\
1(4.35 \%) \\
1(4.35 \%) \\
17(73.91 \%)\end{array}$ & $\begin{array}{l}0(0 \%) \\
0(0 \%) \\
0(0 \%) \\
0(0 \%) \\
9(100 \%)\end{array}$ & 0.162 \\
\hline Relapse & $\begin{array}{l}\text { Repeated } \\
\text { infection } \\
\text { Frist infection }\end{array}$ & $\begin{array}{l}7(30.4 \%) \\
16(69.6 \%)\end{array}$ & $\begin{array}{l}0(0 \%) \\
9(100 \%)\end{array}$ & 0.064 \\
\hline \multicolumn{5}{|c|}{$\begin{array}{l}\text { Rheumatologic } \\
\text { findings }\end{array}$} \\
\hline & $\begin{array}{l}\text { CRP titer, mg/l } \\
\text { RF titer, iu/ml } \\
\text { Uric acid, mg/dl } \\
\text { ESR, } \mathrm{mm} / \mathrm{hr}\end{array}$ & $\begin{array}{l}22.18 \pm 14.4 \\
11.21 \pm 5.56 \\
5.13 \pm 1.42 \\
48.74 \pm 29.27\end{array}$ & $\begin{array}{l}6.72 \pm 1.86 \\
5.79 \pm 1.38 \\
4.70 \pm 1.19 \\
21.89 \pm 7.49\end{array}$ & $\begin{array}{l}0.000 \\
0.002 \\
0.920 \\
0.008\end{array}$ \\
\hline \multicolumn{5}{|c|}{$\begin{array}{l}\text { Rheumatologic } \\
\text { diagnosis }\end{array}$} \\
\hline & $\begin{array}{l}\text { Arthralgia } \\
\text { Arthritis } \\
\text { Polyarthralgia } \\
\text { Polyarthritis } \\
\text { Osteoarthritis } \\
\text { Normal }\end{array}$ & $\begin{array}{l}4(17.4 \%) \\
3(13.0 \%) \\
9(39.1 \%) \\
5(21.7 \%) \\
2(8.8 \%) \\
0(0 \%)\end{array}$ & $\begin{array}{l}0(0 \%) \\
0(0 \%) \\
0(0 \%) \\
0(0 \%) \\
0(0 \%) \\
9(100 \%)\end{array}$ & 0.000 \\
\hline
\end{tabular}

\section{Discussion}

There are three discerned common genotypes of CHIKV: Asia, East/Central/South Africa, and West Africa. These genotypes are presented invasively throughout the Indian Ocean region [8]. Extreme CHIKV infection may cause significant physical impotency [9]. Therefore, this study was taken to elucidate the rheumatologic sequel of postChikungunya infection.

Arthritis/arthralgia is a flagship feature of CHIKV. Many patients were improved within a few weeks, but somewhat up to $50 \%$ reveal chronic joint pain and/or swelling. Once rheumatic symptoms persist for $\geq 3$ months, this indicates a feature of chronic Chikungunya arthritis [10]. In acute CHIKV infection, many cytokines get abundant such as interleukin families (1Ra, $1 \beta, 6,7,8,12$ ) as well as interferon-alpha (IFN- $\alpha$ ). Therefore, $T$ cells and the chemokine $\mathrm{C}-\mathrm{C}$ Ligand 5 /regulated on activation, normal $\mathrm{T}$ cell expressed and secreted (RANTES) decreased in severe infection. Chronic Chikungunya arthritis 
TABLE 2: Symptoms of patients serologically confirmed CHIKV classified according to joint pain status

\begin{tabular}{|c|c|c|c|c|}
\hline Categories & $\begin{array}{l}\text { All confirmed } \\
\text { cases } \\
n=32\end{array}$ & $\begin{array}{l}\text { Persist Joint } \\
\text { pains } \\
n=23\end{array}$ & $\begin{array}{l}\text { No persist joint } \\
\text { pain } \\
n=9\end{array}$ & $\mathbf{P}$ \\
\hline \multicolumn{5}{|c|}{$\begin{array}{l}\text { Rheumatologic } \\
\text { symptoms }\end{array}$} \\
\hline $\begin{array}{l}\text { Wrist pain } \\
\text { Ankle pain } \\
\text { Fingers pain } \\
\text { Elbow pain } \\
\text { Knee pain } \\
\text { Spine pain } \\
\text { Shoulder pain } \\
\text { Feet pain } \\
\text { Swelling }\end{array}$ & $\begin{array}{l}18(56.3 \%) \\
10(31.3 \%) \\
16(50.0 \%) \\
3(9.4 \%) \\
19(59.4 \%) \\
6(18.8 \%) \\
12(37.5 \%) \\
11(34.4 \%) \\
7(21.9 \%)\end{array}$ & $\begin{array}{l}14(60.9 \%) \\
8(34.8 \%) \\
13(56.5 \%) \\
3(13.0 \%) \\
16(69.6 \%) \\
6(26.1 \%) \\
11(47.8 \%) \\
8(34.8 \%) \\
7(30.4 \%)\end{array}$ & $\begin{array}{l}4(44.4 \%) \\
2(22.2 \%) \\
3(33.3 \%) \\
0(0.0 \%) \\
3(33.3 \%) \\
0(0.0 \%) \\
1(11.1 \%) \\
3(33.3 \%) \\
0(0.0 \%)\end{array}$ & $\begin{array}{l}0.001^{*} \\
0.042^{*} \\
0.002^{*} \\
0.270 \\
0.000^{*} \\
0.095 \\
0.009^{*} \\
0.042^{*} \\
0.064\end{array}$ \\
\hline \multicolumn{5}{|c|}{$\begin{array}{l}\text { Duration of joint pain, } \\
\text { months }\end{array}$} \\
\hline $\begin{array}{l}\text { Mean } \pm \text { SD } \\
\text { Median } \\
\text { Range }\end{array}$ & $\begin{array}{l}3.10 \pm 1.83 \\
3.0 \\
1-9\end{array}$ & $\begin{array}{l}3.08 \pm 2.0 \\
3.0 \\
1-9\end{array}$ & $\begin{array}{l}1.78 \pm 0.44 \\
2.0 \\
1-2\end{array}$ & 0.950 \\
\hline \multicolumn{5}{|c|}{$\begin{array}{l}\text { Number of joints } \\
\text { affected }\end{array}$} \\
\hline $\begin{array}{l}\text { Mean } \pm S D \\
\text { Median } \\
\text { Range }\end{array}$ & $\begin{array}{l}2.63 \pm 1.89 \\
3.0 \\
0-6\end{array}$ & $\begin{array}{l}3.65 \pm 1.07 \\
4.0 \\
2-6\end{array}$ & $\begin{array}{l}- \\
- \\
-\end{array}$ & 0.000 \\
\hline
\end{tabular}

${ }^{*} P<0.050$

TABLE 3: Laboratory findings with rheumatologic conditions in the study

\begin{tabular}{|c|c|c|c|c|c|}
\hline Parameters & $\begin{array}{l}\text { Arthritis } \\
n=3\end{array}$ & $\begin{array}{l}\text { Arthralgia } \\
n=4\end{array}$ & $\begin{array}{l}\text { Polyarthralgia } \\
n=9\end{array}$ & $\begin{array}{l}\text { Polyarthritis } \\
n=5\end{array}$ & $\begin{array}{l}\text { Osteoarthritis } \\
n=2\end{array}$ \\
\hline $\begin{array}{l}\text { CRP, } \mathbf{m g} / \mathbf{l} \\
\text { Abnormal } \\
\text { Normal }\end{array}$ & $\begin{array}{l}3(9.4 \%) \\
0\end{array}$ & $\begin{array}{l}1(3.1 \%) \\
3(9.4 \%)\end{array}$ & $\begin{array}{l}8(25 \%) \\
1(3.1 \%)\end{array}$ & $\begin{array}{l}5 \text { (15.6\%) } \\
0\end{array}$ & $\begin{array}{l}2 \text { (6.3\%) } \\
0\end{array}$ \\
\hline $\begin{array}{l}\mathbf{R F}, \mathbf{I U} / \mathbf{m l} \\
\text { Abnormal } \\
\text { Normal }\end{array}$ & $\begin{array}{l}0 \\
3(9.4 \%)\end{array}$ & $\begin{array}{l}4(12.5 \%) \\
0\end{array}$ & $\begin{array}{l}0 \\
9(28.1 \%)\end{array}$ & $\begin{array}{l}5 \text { (15.6\%) } \\
0\end{array}$ & $\begin{array}{l}2(6.3 \%) \\
0\end{array}$ \\
\hline $\begin{array}{l}\text { ESR, mm/hr } \\
\text { Abnormal } \\
\text { Normal }\end{array}$ & $\begin{array}{l}2(6.3 \%) \\
1(3.1 \%)\end{array}$ & $\begin{array}{l}2 \text { (6.3\%) } \\
2 \text { (6.3\%) }\end{array}$ & $\begin{array}{l}5 \text { (15.6\%) } \\
4(12.5 \%)\end{array}$ & $\begin{array}{l}5 \text { (15.6\%) } \\
0\end{array}$ & $\begin{array}{l}2(6.3 \%) \\
0\end{array}$ \\
\hline $\begin{array}{l}\text { Uric acid, } \mathbf{~ m g / d l} \\
\text { Abnormal } \\
\text { Normal }\end{array}$ & $\begin{array}{l}0 \\
3 \text { (9.4\%) }\end{array}$ & $\begin{array}{l}0 \\
4(12.5 \%)\end{array}$ & $\begin{array}{l}0 \\
9 \text { (28.1\%) }\end{array}$ & $\begin{array}{l}1(3.1 \%) \\
4(12.5 \%)\end{array}$ & $\begin{array}{l}0 \\
2 \text { (6.3\%) }\end{array}$ \\
\hline
\end{tabular}

may elevate the levels of IL-6, IL-17, and granulocyte-macrophage-colony stimulating factor (GM-CSF) [11]. IL-17 specifically, may drive chronic joint pain, triggering the upregulation of the other pro-inflammatory cytokines (IL-1, IL-6, tumor necrosis factor (TNF- $\alpha$ ), and matrix metalloproteinase) prompting osteoclastogenesis and bone disintegrations [12]. This study explored that both sexes are more likely to prone the risk of persistent arthralgia/arthritis. This result is not a concordance with other previous studies that have demonstrated females to be at increased risk for persistent arthralgia/arthritis 


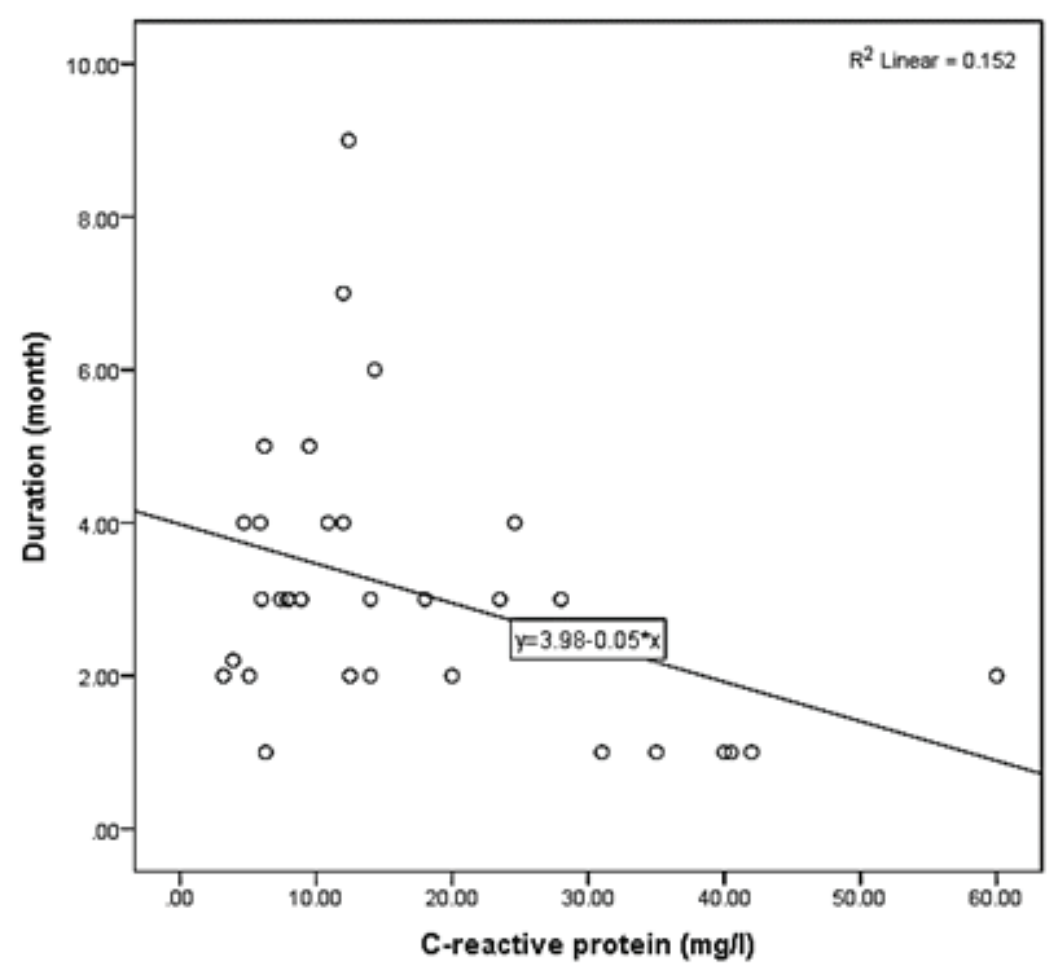

Figure 1: Relationship between C-reactive protein and the duration of CHIKV disease

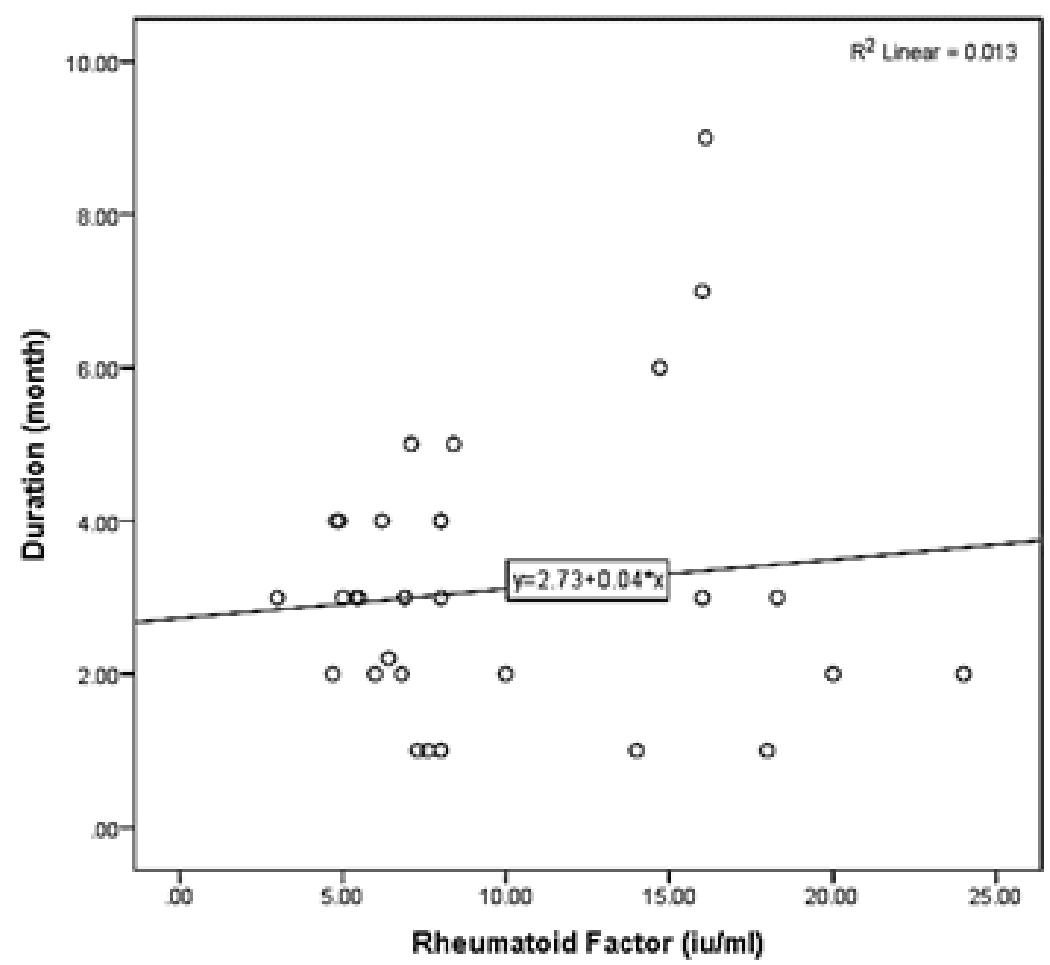

Figure 2: Relationship between rheumatoid factor and the duration of CHIKV disease

[13-15]. However, this unconformity may be excused due to a shortage of sample size. $79.1 \%$ of our studied members have been fulfilled the definition of persistent 
arthralgia/arthritis, which emphatically consented with an ongoing meta-analysis on the occurrence of persistent arthralgia officiated by Rodriquez-Morale et al [16]. Their investigations indicated that in studies with more than 200 members, 34\% of CHIKV infected patients would go on to develop persistent arthritis/arthralgia. This extent is likewise comparable to that as of the detailed by Feldstein et al [17] and is also considerable with our findings.

The intensity of CHIKV infection has recently been answered to be predictive of recovery and long-haul arthritis and arthralgia remarks [18, 19]. Similarly, in our work, a few severe symptoms, including knee pain, wrist pain, shoulder pain, finger pain, which are revealed more serious illness were examined as linked to expanded chronic disease risk. This work highlighted that knee joint pain is a countersign symptom of the disease. A finding also similar to Chang et al [20]. Thus, shoulder joint pain, wrist joint pain, finger joint pain, foot joint pain, and ankle joint pain were found significant in association with CHIKV infection. The prevalence of these symptoms was also explored in Rodriquez-Morale et $a l$ and van Anlst et al [16, 21].

The disease intensity and the following risk of arthralgia/arthritis have been interlinked with viral burden [22]. Remarkably, post-CHIKV infection sequel depends on the duration of the disease onset [23], this surveillance was accentuated to our study. Concerning rheumatologic conditions associated with the present study, polyarthralgia, polyarthritis, arthralgia, and arthritis were represented the most rheumatologic problems. These findings are similar to Heath et $a l$ and Ganu et al [23, 24]. Laboratory findings such as RF, CRP, and ESR were found to be significant in association with Chikungunya infection, this may support the evidence that the presence of increased value of these parameters is a factor implicated in the progression of Chikungunya complications [23]. Besides, this study revealed that age and the number of joint affected were also considered factors that enhance in augments of Chikungunya sequel. A significant increase in CRP results was noted in $59.4 \%$ of the study. These findings concur with Ganu et al [24]. ESR was elevated in $50 \%$ of patients as a screening marker of inflammation. RF was significantly positive in $34.4 \%$. A determination was also likewise detected previously [20, 24]. The high titer of RF could be falsely positive or its output could have been activated by CHIKV disease [24]. This study was subject to some limitations summarized as, this is a short communication survey with very limited sample size, in addition to that, we have neglected other physical symptoms of individuals who did not seek consultation. Recall bias could not be ruled out. A prospective study with considerable expansion should be planned to monitor the structural joint damage, the therapeutic drugs used, 
combined molecular and serological characterization of CHIKV, and more laboratory sophisticated analyses.

\section{Conclusion}

Polyarthralgia was characterized as the dominant inflammatory sequel in this study, followed by polyarthritis, and arthralgia for at least 3 months. Knee joint pain represented a significant dilemma post-CHIKV infection. Effective cure post-CHIKV symptoms sequel could improve the health of an individual.

\section{Acknowledgement}

We wish to convey our profound gratitude to all patients who availed themselves voluntary to participate in this survey.

\section{Competing Interest}

The author declares that they have no competing interests.

\section{Availability of Data and Material}

The data which are published are always reproducible by investigators

\section{Funding}

None

\section{Ethics Approval}

This study was ratified by a regional ethical review committee. Informed consent was taken from each participant of the study. 


\section{References}

[1] Manimunda, S. P., Vijayachari, P., Uppoor, R., et al. (2010). Clinical progression of chikungunya fever during acute and chronic arthritic stages and the changes in joint morphology as revealed by imaging. Transactions of the Royal Society of Tropical Medicine and Hygiene, vol. 104, no. 6, pp. 392-399.

[2] Gould, L. H., Osman, M. S., Farnon, E. C., et al. (2008). An outbreak of yellow fever with concurrent chikungunya virus transmission in South Kordofan Sudan 2005. Transactions of the Royal Society of Tropical Medicine and Hygiene, vol. 102, no. 12, pp. 1247-1254.

[3] Al-Gasseer, N., El Bushra, H. E., Yeneabat, A., et al. (2019). Countrywide outbreak of acute watery diarrhea in Sudan, 2016-2018. EC Emergency Medicine and Critical Care, vol. 3, no. 5, pp. 274-284.

[4] Leparc-Goffart, I., Nougairede, A., Cassadou, S., et al. (2014). Chikungunya in the Americas. Lancet, vol. 383, p. 514.

[5] Weaver, S. C. and Lecuit, M. (2015). Chikungunya virus and the global spread of a mosquito-borne disease. New England Journal of Medicine, vol. 372, pp. 1231-1239.

[6] Powers, A. M. (2015). Risks to the Americas associated with the continued expansion of chikungunya virus. Journal of General Virology, vol. 96, pp. 1-5.

[7] Kwoh, C. K., Maclean, C., Anderson, L. G., et al. (2008). Rheumatoid Arthritis Physician Performance Management Set. National Committee for Clinical Assurance, Physician consortium for Performance Improvement, American College of Rheumatology. Available from: http://www.ama-assn.org/ama1/pub/upload/mm/pcpi/rheumatoidarthritis.pdf.

[8] Ali, A. N., Hui, C. J., Prajapati, S. K., et al. (2018). Knowledge and awareness regarding Chikungunya: a cross-sectional study among healthcare students in a private university, Malaysia. MOJ Bioequivalence \& Bioavailability, vol. 5, no. 6, pp. $293 \rrbracket 298$.

[9] Charlys da Costa, A., Thézé, J., Komninakis, S., et al. Spread of chikungunya virus east/central/south African genotype in Northeast Brazil. Emerging Infectious Diseases 2017, vol. 23, no. 10, pp. 1742-1744.

[10] Staples, J. E., Breiman, R. F., and Powers, A. M. (2009). Chikungunya fever: an epidemiological review of a re-emerging infectious disease. Clinical Infectious Diseases, vol. 49, no. 6, pp. 942-948.

[11] Schilte, C., Staikowsky F, Couderc T, et al. (2013). Chikungunya virus-associated longterm arthralgia: a 36-month prospective longitudinal study. PLOS Neglected Tropical 
Diseases, vol. 7, no. 3, p. e2137.

[12] Chow, A., Her Z, Ong EK, et al. (2011). Persistent arthralgia induced by chikungunya virus infection is associated with interleukin- 6 and granulocyte macrophage colony stimulating factor. The Journal of Infectious Diseases, vol. 203, no. 2, pp. 149-157.

[13] Chen, W., Foo SS, Rulli NE, et al. (2014). Arthritogenic alphaviral infection perturbs osteoblast function and triggers pathologic bone loss. Proceedings of the National Academy of Sciences of the United States of America, vol. 111, no. 16, pp. 6040-6045.

[14] Gerardin, P., Fianu, A., Michault, A., et al. (2013). Predictors of Chikungunya rheumatism: a prognostic survey ancillary to the TELECHIK cohort study. Arthritis Research \& Therapy, vol. 15, p. R9.

[15] Elsinga, J., Gerstenbluth, I., van der Ploeg, S., et al. (2017). Long-term Chikungunya sequelae in Curacao: burden, determinants and a novel classification tool. Journal of Infectious Diseases, vol. 216, pp. 573-581.

[16] Mohd Zim, M. A., Sam, I. C., Omar, S. F., et al. (2013). Chikungunya infection in Malaysia: comparison with dengue infection in adults and predictors of persistent arthralgia. Journal of Clinical Virology, vol. 56, p. 141-145.

[17] Rodriguez-Morales, A. J., Cardona-Ospina, J. A., Fernanda Urbano-Garzon, S., et al. (2016). Prevalence of post-Chikungunya infection chronic inflammatory arthritis: a systematic review and meta-analysis. Arthritis Care \& Research, vol. 68, pp. 18491858.

[18] Feldstein, L. R., Rowhani-Rahbar, A., Staples, J. E., et al. (2016). Persistent arthralgia associated with Chikungunya virus outbreak, US Virgin Islands, December 2014February. Emerging Infectious Diseases, vol. 23, no. 4, pp. 673-676.

[19] Yaseen, H. M., Simon, F., Deparis, X., et al. (2014). Identification of initial severity determinants to predict arthritis after Chikungunya infection in a cohort of French gendarmes. BMC Musculoskeletal Disorders, vol. 15, p. 249.

[20] Fritzell, C., Raude, J., Adde, A., et al. (2016). Knowledge, attitude and practices of vector- borne disease prevention during the emergence of a new arbovirus: implications for the control of Chikungunya virus in French Guiana. PLOS Neglected Tropical Diseases, vol. 10, p. e0005081.

[21] Chang, A. Y., Encinales, L., Porras, A., et al. (2018). Frequency of chronic joint pain following Chikungunya virus infection: a Colombian cohort study. Arthritis \& Rheumatology, vol. 70, no. 4, pp. 578-584.

[22] van Aalst, M., Nelen, C. M., Goorhuis, A., et al. (2017). Long-term sequelae of chikungunya virus disease: a systematic review. Travel Medicine and Infectious Disease, vol. 15, pp. 8-22. 
[23] Hoarau, J. J., Jaffar Bandjee, M. C., Krejbich Trotot, P., et al. (2010). Persistent chronic inflammation and infection by Chikungunya arthritogenic alphavirus in spite of a robust host immune response. Journal of Immunology, vol. 184, pp. 5914-5927.

[24] Heath, C. J., Lowther, J., Noël, T. P., et al. (2018). The identification of risk factors for chronic Chikungunya arthralgia in Grenada, West Indies: a cross-sectional cohort study. Open Forum Infectious Diseases, vol. 5, no. 1, pp. 1-10. 